\title{
Distribution Network Planning Evaluation Considering Risk Cost
}

\author{
Jianwei Xu, Haifeng Su, Zhirui Liang \\ School of North China Electric Power University, Baoding 071000, China
}

\begin{abstract}
Keywords: Distribution Network, Planning, Life Cycle Cost, Risk.
\end{abstract}
\begin{abstract}
There are many uncertain factors that affect the planning of power network, and these uncertain risk factors appear in all stages of the life cycle. The uncertainty of load and electricity price directly affects the whole life cycle cost of the plan. In the whole life cycle cost calculation of power system planning, the uncertainty of load and electricity price is included, so that the whole life cycle cost evaluation of power system planning is more reasonable.
\end{abstract}

\section{Introduction}

The planning and design of the distribution network is based on the load forecasting result and the location of the power supply point for the given target year, and obtain the minimum investment grid construction to meet the technical requirements. The power network planning process can be divided into two parts: planning scheme generation and planning optimization. The economic evaluation of the planning scheme generally only analyzes and calculates the initial investment in detail, and the running cost and outage cost after the completion of the distribution network are very rough. In fact, because the distribution network life cycle is very long, planning and design program operation and maintenance costs and power outages even higher than its initial cost of investment costs [1]. Reasonable system planning can effectively save the investment and improve the economic and social benefits of the power grid. Therefore, it is necessary to carry out the whole life cycle evaluation of the grid plan. When the life cycle management concept is applied to the distribution network planning, the costs of investment, operation and maintenance, failure and discarding are considered.

There are many uncertainties that affect the planning of the power grid, and these uncertain risk factors appear at all stages of the life cycle. In [2], the triangular fuzzy number is used to describe the uncertainty of load, and its influence on the substation planning is included in the mathematical model. In the literature [3], the uncertainty of the load, the uncertainty of land expropriation cost and the uncertainty of social compensation are respectively described by simplified probability density function. The objective function with maximum expected profit in the whole life cycle is established, but the quantification of various uncertain risk factors is carried out under the influence of neglecting some actual situations. . The uncertainty of load and electricity price will directly affect the life cycle cost and the risk and efficiency of the scheme. Based on the LCC theory, this paper carries out risk identification for the whole process of planning, operation, maintenance and disposal of distribution network. The uncertainty of the load and the uncertainty of the electricity price are quantified respectively, which makes the scheme more suitable for the actual situation while satisfying the economy and reliability.

\section{Uncertainty Risk Factors in Power Network Planning Model}

The research on the risk of construction project of distribution network is still at the theoretical level. There are not many references available for research, so it is necessary to quantify the uncertain risk factors. For all kinds of uncertain risks faced by distribution network planning, this paper analyzes the whole life cycle process and considers the uncertainties of load and electricity price.

\subsection{Uncertainty model of load}

The future load demand is mainly affected by domestic and international economic situation, industrial structure policy, energy-saving policy, energy consumption structure and other factors. Therefore, the future load is unavoidably uncertain. Through the statistical analysis of the historical 
load data in a region for a year, it is found that the load value is a random variable obeying the normal distribution. Therefore, the uncertain load of the planning area is shown as formula (1):

$$
P=\int_{\mu-3 \sigma}^{\mu+3 \sigma} x f_{Q}(x) d x=\int_{\mu-3 \sigma}^{\mu+3 \sigma} x \frac{1}{\sqrt{2 \pi} \sigma} e^{-(x-\mu)^{2} /\left(2 \sigma^{2}\right)} d x
$$

$\mathrm{P}$ is the uncertain load of the planning area; $\mathrm{f}_{\mathrm{Q}}(\mathrm{x})$ is the probability density function of the load in the planning area; $\mu$ is the mean of the normal distribution; $\sigma^{2}$ is the variance. The probability that the load value is within $(\mu-3 \sigma, \mu+3 \sigma)$ is $99.74 \%$, its value in $(\mu-3 \sigma, \mu+3 \sigma)$ is almost certain. Generally, the load points in the region are independent of each other, and their sum or difference still obeys the normal distribution, The uncertainty interval of load point $\mathrm{j}$ is $\left[\mu_{\mathrm{j}}-3 \sigma_{\mathrm{j}}, \mu_{\mathrm{j}}+3 \sigma_{\mathrm{j}}\right]$.

\subsection{Uncertainty model of electricity price}

There are many factors that affect the price of electricity, including macro-factors and microfactors, mainly government policies, national economic growth rate, power supply and demand, system load rate and so on. In the electricity market environment, electricity demand and sales price are becoming interrelated economic variables, and electricity price changes with demand, which in turn affects demand [4]. For markets with elastic loads, the function of electricity price and load is:

$$
\beta=a-b Q=\mathrm{a}-\mathrm{b} \int_{-\infty}^{+\infty} 8760 x f_{Q}(x) d x
$$

$\beta$ is the uncertain price; $Q$ is the indefinite load demand for the planning area; $a$ and $b$ are constants not less than zero; $f_{Q}(x)$ is the probability density function of the load in the planning area.

\section{Life Cycle Cost Model for distribution network Planning}

The life cycle cost of the distribution network refers to the overall costs incurred during the whole period from design to discarding, including the initial investment $\operatorname{cost} \mathrm{C}_{\mathrm{I}}$, the operation and maintenance cost $C_{O}$, the power failure loss cost $C_{F}$ and the disposal disposal cost $C_{D}$. The core content of the LCC of the distribution network planning is to analyze and calculate the proposal LCC, to find the best plan of distribution network under the premise of satisfying safety, efficiency and environmental protection, and to create the biggest economic benefit, social benefit and environmental benefit. . In this paper, the uncertainties of load and the uncertainty of electricity price are taken into account in the cost calculation of LCC.

\subsection{Substation $\mathrm{LCC}_{\mathrm{S}}$ model}

$$
\mathrm{LCC}_{\mathrm{S}}=\mathrm{C}_{\mathrm{S}-\mathrm{I}}+\left(\mathrm{C}_{\mathrm{S}-\mathrm{O}}+\mathrm{C}_{\mathrm{S}-\mathrm{M}}+\mathrm{C}_{\mathrm{S}-\mathrm{F}}\right) \mathrm{PV}_{\text {sum }}+\mathrm{C}_{\mathrm{S}-\mathrm{D}} \mathrm{PV}
$$

Among them, $\mathrm{C}_{S-I}, \mathrm{C}_{S-O}, \mathrm{C}_{S-M}, \mathrm{C}_{S-F}, \mathrm{C}_{\mathrm{S}-\mathrm{D}}$ are the initial investment cost, operation cost, maintenance cost, failure cost and disposal cost respectively. The initial investment cost includes equipment purchase cost and installation cost.

$$
\begin{gathered}
\mathrm{C}_{\mathrm{S}-\mathrm{I}}=\sum_{\mathrm{i}=1}^{\mathrm{N}} \mathrm{C}_{\mathrm{i}} \mathrm{S}_{\mathrm{i}} \\
\mathrm{C}_{\mathrm{S}-\mathrm{O}}=\sum_{\mathrm{i}=1}^{\mathrm{N}} \sum_{\mathrm{a} \in \mathrm{A}_{\mathrm{i}}}\left(\mathrm{P}_{\mathrm{iao}}+\rho_{\mathrm{ia}}^{2} \mathrm{P}_{\mathrm{iak}}\right) \tau_{\mathrm{max}} \beta \\
\mathrm{C}_{\mathrm{S}-\mathrm{M}}=\sum_{\mathrm{i}=1}^{\mathrm{N}} \alpha \mathrm{C}_{\mathrm{i}} \mathrm{S}_{\mathrm{i}} \\
\mathrm{C}_{\mathrm{S}-\mathrm{F}}=\int_{\mu-3 \sigma}^{\mu+3 \sigma} \mathrm{xf}_{\mathrm{Q}}(\mathrm{x}) \mathrm{dx}(\mathrm{R}+\theta) \mathrm{t}_{\mathrm{si}} \lambda_{\mathrm{si}} \\
\mathrm{C}_{\mathrm{S}-\mathrm{D}}=\left(v_{\mathrm{b}}-v_{\mathrm{c}}\right) \mathrm{C}_{\mathrm{S}-\mathrm{I}}
\end{gathered}
$$

$\mathrm{PV}_{\text {sum }}=\left[(1+r)^{\mathrm{n}}-1\right] /\left[\mathrm{r}(1+\mathrm{r})^{\mathrm{n}}\right]$ is the conversion factor of present value of annual investment cost; $n$ refers to the project life cycle; $r$ is the discount rate; $C_{i}$ is the substation unit capacity cost; $S_{i}$ is the capacity of substation $\mathrm{i}$; $\mathrm{P}_{\mathrm{iao}}$ is the no-load loss of transformer a in substation $\mathrm{i}$; $\mathrm{P}_{\mathrm{iak}}$ is the load loss of transformer a in substation $\mathrm{i} ; \rho_{\mathrm{ia}}$ is the load rate of transformer a in substation $\mathrm{i} ; \beta$ represents the uncertain load; $\mathrm{R}$ represents the planning area ratio; $\theta$ represents the sale of electricity profits; $t_{s i}$ represents the transformer fault isolation time; $\lambda_{s i}$ represents the transformer 
failure rate; $v_{-} b$, repersents the conversion coefficient of disposal; $v_{c}$ repersents the residual value conversion factor.

\subsection{High - voltage inlet line $\mathrm{LCC}_{\mathrm{HV}}$ model}

$$
\mathrm{LCC}_{\mathrm{HV}}=\mathrm{C}_{\mathrm{HV}-\mathrm{I}}+\left(\mathrm{C}_{\mathrm{HV}-\mathrm{O}}+\mathrm{C}_{\mathrm{HV}-\mathrm{M}}+\mathrm{C}_{\mathrm{HV}-\mathrm{F}}\right) \mathrm{PV}_{\mathrm{sum}}+\mathrm{C}_{\mathrm{HV}-\mathrm{D}}
$$

$\mathrm{C}_{\mathrm{HV}-\mathrm{I}}, \mathrm{C}_{\mathrm{HV}-\mathrm{O}}, \mathrm{C}_{\mathrm{HV}-\mathrm{M}}, \mathrm{C}_{\mathrm{HV}-\mathrm{F}}, \mathrm{C}_{\mathrm{HV}-\mathrm{D}}$ are the initial investment cost, operation cost, maintenance cost, failure cost and disposal cost of the high-voltage inlet line of the substation respectively. Considering the overhead line residual income is small, the cost of environmental governance and the residual income line offset.

$$
\begin{gathered}
\mathrm{C}_{\mathrm{HV}-\mathrm{I}}=\sum_{\mathrm{q}=1}^{\mathrm{M}} \sum_{\mathrm{i}=1}^{\mathrm{N}} \mathrm{l}_{\mathrm{HV}-\mathrm{qi}} \mathrm{c}_{\mathrm{h}} \\
\mathrm{C}_{\mathrm{HV}-\mathrm{O}}=\sum_{\mathrm{q}=1}^{\mathrm{M}} \sum_{\mathrm{i}=1}^{\mathrm{N}} \beta_{\mathrm{h}} \mathrm{l}_{\mathrm{HV}-\mathrm{qi}}\left(\sum_{\mathrm{j} \epsilon \mathrm{j}_{\mathrm{i}}} \mathrm{W}_{\mathrm{j}}\right)^{2} \\
\mathrm{C}_{\mathrm{HV}-\mathrm{M}}=\sum_{\mathrm{q}=1}^{\mathrm{M}} \sum_{\mathrm{i}=1}^{\mathrm{N}} \alpha \mathrm{l}_{\mathrm{HV}-\mathrm{qi}} \mathrm{c}_{\mathrm{h}} \\
\mathrm{C}_{\mathrm{HV}-\mathrm{F}}=\sum_{\mathrm{q}=1}^{\mathrm{M}} \sum_{\mathrm{i}=1}^{\mathrm{N}}\left[(\mathrm{R}+\theta) \mathrm{t}_{\mathrm{hi}} \lambda_{\mathrm{hi}} \mathrm{l}_{\mathrm{HV}-\mathrm{qi}} \sum_{\mathrm{j} \epsilon_{\mathrm{i}}} \mathrm{W}_{\mathrm{j}}\right]
\end{gathered}
$$

$\mathrm{M}$ represents the number of the high-voltage power point; $\mathrm{l}_{\mathrm{HV}-\mathrm{qi}}$ represents the distance from the high-voltage power point q to substation $\mathrm{i}$; $\mathrm{c}_{\mathrm{h}}$ represents investment cost of high-voltage inlet line per unit length; $\beta_{\mathrm{h}}=\beta \beta_{\mathrm{h} 2} \beta_{\mathrm{h} 3} /\left(\mathrm{U}_{\mathrm{h}}^{2} \cos ^{2} \varphi_{\mathrm{h}}\right) \beta$ represents the uncertain price; $\beta_{\mathrm{h} 2}$ represents the resistance of the high-voltage line per unit length; $\beta_{\mathrm{h} 3}$ represents the maximum load loss of time of the high-voltage line; $U_{h}$ represents the rated line voltage of the high voltage line; $\cos \varphi_{\mathrm{h}}$ represents the power factor of the high voltage side; $W_{j}=\int_{\mu_{j}-3 \sigma_{j}}^{\mu_{j}+3 \sigma_{j}} x_{j} f_{Q}(x) d x$ represents the uncertain load of the load point $j$; $t_{h i}$ represents the mean time to repair of the high-voltage line of substation $i ; \lambda_{h i}$ represents the failure rate the high-voltage line of substation $i$.

Since the configuration and calculation of $\mathrm{LCC}_{\mathrm{LV}}$ is similar to that of $\mathrm{LCC}_{\mathrm{HV}}$, they won't be covered here.

\section{Application}

The predicted total amount of load growth of a development zone is $128.32 \mathrm{MW}$ after 10 years, the maximum load utilization hours is $5500 \mathrm{~h}$, and the load center position and size are shown in table 1 . In order to meet the load demand, need to build $35 \mathrm{kV}$ substation. In the process of uncertain load calculation, the average value of the load probability density function of the development zone is determined by mean value and variance of history fitting normal distribution. The mean value of the load density function $\mu=109.63$, and the variance approximation is taken as the average value of the historical load data of the development zone. The historical load variance $\sigma^{2}=38.81$; In the uncertainty calculation of the electricity price, the coefficient $a=65, b=9.14 \times 10^{-8}$ is determined by fitting the original data of different price and charge in the literature[5]. Three feasible planning schemes were evaluated by using this model respectively

Table1 capacity and position of load nodes

\begin{tabular}{|c|c|c|c|c|c|}
\hline node & $\begin{array}{c}\text { coordinate } \\
/ \mathrm{km}\end{array}$ & $\begin{array}{c}\text { Maximum load } \\
\text { value /MW }\end{array}$ & node & $\begin{array}{c}\text { coordinate } \\
/ \mathrm{km}\end{array}$ & $\begin{array}{c}\text { Maximum } \\
\text { load value } \\
/ \mathrm{MW}\end{array}$ \\
\hline 1 & $(2.65,3.11)$ & 4.62 & 13 & $(4.21,3.12)$ & 6.23 \\
\hline 2 & $(3.56,4.61)$ & 2.01 & 14 & $(5.65,3.21)$ & 7.25 \\
\hline 3 & $(2.89,5.21)$ & 13.21 & 15 & $(6.25,5.12)$ & 4.12 \\
\hline 4 & $(2.59,2.36)$ & 5.23 & 16 & $(3.21,4.21)$ & 5.45 \\
\hline 5 & $(2.64,4.21)$ & 5.69 & 17 & $(3.45,5.23)$ & 6.10 \\
\hline
\end{tabular}




\begin{tabular}{|c|c|c|c|c|c|}
\hline 6 & $(2.19,3.12)$ & 5.02 & 18 & $(4.21,6.55)$ & 5.31 \\
\hline 7 & $(3.64,3.26)$ & 2.10 & 19 & $(3.42,3.01)$ & 12.66 \\
\hline 8 & $(4.12,5.52)$ & 2.65 & 20 & $(5.71,7.21)$ & 3.55 \\
\hline 9 & $(4.25,3.25)$ & 4.12 & 21 & $(7.12,6.35)$ & 4.65 \\
\hline 10 & $(4.85,3.05)$ & 4.56 & 22 & $(5.49,6.01)$ & 4.87 \\
\hline 11 & $(4.59,3.55)$ & 3.26 & 23 & $(3.56,6.51)$ & 6.25 \\
\hline 12 & $(5.21,3.12)$ & 5.10 & 24 & $(6.45,7.21)$ & 4.31 \\
\hline
\end{tabular}

Table2 The life cycle cost evaluation results (ten thousand yuan)

\begin{tabular}{|c|c|c|c|c|c|c|c|}
\hline Scheme & Proposal & CI & $\mathrm{CO}$ & $\mathrm{CM}$ & $\mathrm{CF}$ & $\mathrm{CD}$ & LCC \\
\hline 1 & $\begin{array}{c}23 \times 20 \mathrm{MV} \cdot \mathrm{A} \\
\text { substations } \\
13 \times 16 \mathrm{MV} \cdot \mathrm{A} \\
\text { substations }\end{array}$ & 7592.62 & 8488.34 & 1118.18 & 299.87 & - 376.37 & 17122.65 \\
\hline 2 & $\begin{array}{c}13 \times 20 \mathrm{MV} \cdot \mathrm{A} \\
\text { substations } \\
3 \mathrm{3} \times 16 \mathrm{MV} \cdot \mathrm{A} \\
\text { substations }\end{array}$ & 8416.65 & 6417.82 & 1239.54 & 236.04 & -410.19 & 15899.85 \\
\hline 3 & $\begin{array}{c}13 \times 20 \mathrm{MV} \cdot \mathrm{A} \\
\text { substations } \\
43 \times 16 \mathrm{MV} \cdot \mathrm{A} \\
\text { substations }\end{array}$ & 10130.01 & 6457.17 & 1491.86 & 243.00 & - 498.99 & 17823.05 \\
\hline
\end{tabular}

As can be seen from Table 2, the program 2 is the optimal planning scheme. From the LCC data can be seen that the scheme with the least initial investment is not the optimal solution for the whole life cycle. The operation cost, maintenance cost and failure cost of the system occupy a large proportion, so the analysis based on LCC is of great significance. In this paper, the uncertainties of the load and the electricity price are taken into account in the cost of each stage of the whole life cycle, which makes the calculation result more practical.

\section{Conclusion}

In the face of the increasing number of uncertain risk factors in the process of distribution network planning, the uncertainties of the load and the uncertainty of the electricity price are included in the planning cost based on the LCC theory, and a numerical example is given to demonstrate its scientificity and practicability. There are many uncertain risk factors in the distribution network planning, and it is meaningful to deeply study the effect of other influencing factors on planning scheme evaluation.

\section{References}

[1] Shengnan Cao. Study on electrical distribution network planning project evaluation based on life cycle cost [D].China: North China Electric Power University.2012.

[2] Fuliang Gao, Peng Zhang,Xue Sai,et al.Substations locating and sizing in uncertainty load environment[J].Power System Protection and Control.Vol.38(2010)No.15,p.75-80.

[3] Yongxiu He,Tao Luo,Rui Fang,et al.Substation locating optimization based on risk analysis [J]. Journal of North China Electric Power University.Vol.38(2011)No.3,p.53-57.

[4] Jun Li,Junyong Liu,Lianfang Xie,et al.[J]. Electric Power Automation Equipment. Vol.32 (2012) No.4,p.16-19.

[5] Ping Yuan.The policy-type adjustment model of the sale electric and its analysis[D].China: Hunan University.2009. 